\title{
Work and Management in Nursing
}

\section{Alexandre Pazetto Balsanelli' \\ ORCID: 0000-0003-3757-1061}

'Adjunct Professor at Escola Paulista de Enfermagem, from Universidade Federal de São Paulo. Associate Editor at Revista Brasileira de Enfermagem. São Paulo, São Paulo, Brazil.

How to cite this article: Balsanelli AP. Work and Management in Nursing. Rev Bras Enferm [Internet]. 2019;72(Suppl 1):1. [Thematic Issue: Work and Management in Nursing] DOI: http://dx.doi.org/10.1590/0034-7167.201972supl01
The nurse's working process is dynamic and requires several skills in order to be well accomplished. The current world has been encouraging health professional to pursue more knowledge to carry out tasks efficiently and effectively. Management has the same needs. We should instrumentalize ourselves to perform it with excellence and stand out in the Health setting. However, some issues deserve to be put on the agenda and they will be presented in the following paragraphs.

Care, as the profession's core, is the Nursing's heart. Management arranges all required resources in order to make assistance results profitable. Therefore, there is no dissociation in this symbiosis. In the complementarity of actions, who benefits is the user of the service and the professionals who perform it as members of a team imbued with the same objective.

Are all nurses able to manage? Are necessary skills to perform the care related to management? These questions raise from different settings and refer to the professional's training focused on care. In order to take over a function or strategic position it is primary to pursue a specific instrumentalization that subsidizes this challenge. That is why Administration, as Science, teaches us show to perform management with expertise.

Management in Nursing is ultimate and it cannot be left to chance. Trying, making mistakes, learning with experience of others are interesting knowledge strategies, but they cannot be the only ones used. The search for Evidence-Based Practice is primordial, so we can develop a constant and sustainable knowledge in this field. All are recruited in favor to this movement: undergraduates and post-graduation students, residents, auxiliary nurses, supervisors, coordinators, managers, superintendents and other professionals belonging to different positions in order to use research methods that will produce innovative practices in different assistance environments.

Nurses are expected to be audacious and committed with the change of assistance and management practices. We are the professionals inspired by Florence Nightingale capable of performing this change with empowerment. Conformism, pessimism and other feelings related will not allow us to progress. We must leave "status quo" and embrace a position of an inspiring and visionary leadership so that we can reach high levels in search for commitment with the profession.

Such empowerment will allow nurses to perform a professional practice that will meet the needs of public policies in effect and also will modify all non-favourable settings for the Health area development in the country and in the world.

It is up to nurses play the role as protagonists by using management as a principle in order to make their work responsible for fruitful changes and for bringing benefits for population. 